\title{
El sentido de la comunicación en adolescentes de una Casa Hogar en Chiapas
}

\section{The sense of communication in adolescents of a House Home in Chiapas}

- Verónica Rodríguez

Universidad Autónoma de Chiapas, México

$$
\left(\begin{array}{l}
\text { Fecha de recepción: } 27 \text { de marzo de } 2019 \\
\text { Fecha de aprobación: } 15 \text { de noviembre de 2019}
\end{array}\right)
$$

DOI: http://dx.doi.org/10.15304/ricd.3.11.5917

\section{NOTAS BIOGRÁFICAS}

Verónica Rodríguez es maestra en Estudios Culturales, especialista en Procesos Culturales Lectoescritores y licenciada en Sistemas Computacionales por la Universidad Autónoma de Chiapas (UNACH), titulada por mérito académico y graduada con Mención Honorífica en la carrera y ambos posgrados en la misma institución. Tiene un diplomado en Alfabetización Digital y acreditaciones en Competencias Tecnológicas para la productividad. Ha realizado trabajo de desarrollo e investigación en las áreas de educación, cultura, comunicación y tecnologías. Ha participado como ponente en congresos nacionales e internacionales.

Contacto: sudveronica1@gmail.com

\section{Resumen}

El presente artículo examinó la realidad social en catorce adolescentes de secundaria en una Casa Hogar de Tuxtla Gutiérrez, Chiapas, con el propósito de interpretar el sentido de la comunicación que han construido los menores, para reconocer si existen códigos opresores y modelos estándares que se contrarresten con la noción de concientización, mismos que les impidan tener una visión amplia de las formas de vida al interactuar con la sociedad y poseer una postura crítica para desarrollarse, mediante tres acciones principales: primero, el conocimiento de las bases bajo las que se establecen los procesos comunicacionales a través de las trayectorias discursivas, historias y experiencias de vida; segunda, la identificación de la relación que existe entre sujeto, cultura y poder en la construcción del sentido; y por último, el análisis de los datos, a través de la triangulación de las categorías, subcategorías y dimensiones encontradas. En la investigación se empleó la metodología cualitativa, con la combinación de dos perspectivas: la de interpretación y la Investigación Acción Participativa (IAP) desde un enfoque crítico, donde las categorías consideradas fueron: Un marco microsociológico, pautas psicosociológicas y características individuales, las subcategorías fueron: instrumental, valorativa, pertenencia, seguridad, disciplinar, religiosa y uso del poder, en las dimensiones objetivo-subjetivas. Los resultados obtenidos se presentaron en tres perspectivas: En la política, el uso del poder discursivo jerárquico vertical, la imposición de la religión como modelo de adoctrinamiento para la modificación del comportamiento; en la cultura, la manipulación de las subjetividades, a través de la domesticación de sentimientos por medio de la disciplina para ser buenas personas y la adquisición de valores en el camino de llegar a ser buenos cristianos; y en el plano económico, la construcción de un sentido instrumental-material, la inducción a una programación visual alienante y el posicionamiento de marketing. 


\section{Abstract}

This article examined the social reality in fourteen high school teenagers in a House Home of Tuxtla Gutiérrez, Chiapas, with the purpose of interpreting the sense of communication that minors have constructed, o recognize if there are oppressive codes and standard models that are counterbalanced by the notion of awareness, which prevent them from having a broad vision of life forms when interacting with society and have a critical position to develop, through three main actions: first, the knowledge of the bases under which the communicational processes are established through the discursive trajectories, histories and life experiences; second, the identification of the relationship that exists between subject, culture and power in the construction of sense; and finally, the analysis of the data, through the triangulation of the categories, subcategories and dimensions found. This research used the qualitative methodology, with the combination of two perspectives: the interpretation and the Participatory Action Research (IAP) from a critical approach, where the categories considered were: A microsociological framework, psychosociological guidelines and individual characteristics, the subcategories were: instrumental, evaluative, belonging, security, disciplinary, religious and use of power, in the objective-subjective dimensions. The results obtained were presented in three perspectives: In politics, the use of vertical hierarchical discursive power, the imposition of religion as a model of indoctrination for the modification of behavior; in the culture, the manipulation of subjectivities, through the domestication of feelings through discipline to be good people and the acquisition of values in the way of becoming good Christians; and in the economic sphere, the construction of an instrumentalmaterial sense, the induction to an alienating visual programming and marketing positioning.

\section{Palabras clave}

Comunicación, sentido social, adolescentes, casa hogar, proceso crítico.

\section{Keywords}

Communication, social sense, teenagers, house home, critical process.

\section{Sumario}

1. Introducción. Comunicación en adolescencias institucionalizadas

2. Marco teórico. Sentido de la comunicación

3. Metodología. Proceso en la indagación del sentido comunicativo

4. Resultados. Producción del sentido en comunicación

5. A modo de conclusión. Educación crítica en comunicación

\section{Summary}

1. Introduction. Communication in institutionalized teens

2. Theoretical framework. Sense of communication

3. Methodology. Process in the investigation of the communicative sense

4. Results. Production of sense in communication

5. By way of conclusion. Critical education in communication 


\section{INTRODUCCIÓN}

La comunicación se ha definido desde diversas perspectivas para explicar los fenómenos de las relaciones sociales. Se puede afirmar que, al hablar de la producción de sentido, ésta no pertenece a una disciplina en particular, sino que se genera en los procesos de intercambio discursivo de los diversos actores ubicados en contextos culturales distintos, incluidas las instituciones, mediante prácticas comunicativas cotidianas, ya sean, presenciales o virtuales de lo que se percibe como realidad para generar significados grupales, es decir, se perpetúa y desarrolla en una estructura social,

Para algunos autores la comunicación tiene influencia a nivel macro en las relaciones humanas y los mecanismos para el intercambio de datos, tanto en el trato de la vida cotidiana como el ambiente virtual para reducir tiempos, precios y trámites (Richard, 2011). Se considera un espacio para la producción, circulación, consumo de contenidos, mensajes, informaciones, imágenes y sonidos. Pasquali no la conceptualiza en una mera técnica para transmitir información, la vincula con las tecnologías, sociología, cultura, política, psicología y antropología; la define como: "la matriz en la que están enclavadas todas las actividades" (2007, p. 33), en cualquier situación o representación mediante la cual los objetos no tendrían sentido por sí mismos, por el contrario, estos se encuentran en una relación donde participan en el proceso. Desde el punto de vista de Shannon se trata de generar significados referentes a la realidad desde "las Ilamadas prácticas comunicativas, caracterizadas por un elevado nivel de organización, de continuidad temporal y de previsibilidad, pero también de flexibilidad y de adaptabilidad a cada situación concreta" (Anolli, 2017, p. 17).

Las prácticas comunicativas que conducen la actuación tienen un proceso de producción de sentido a partir de la emocionalidad, el contexto y la subjetividad del sujeto, su origen es derivado de historias, experiencias, costumbres y tradiciones; las cuales hacen uso de imágenes y modelos cognitivos para interactuar con los objetos creados para comunicarse con los otros seres humanos en una mediación social. El tener un sentido social es una forma lógica o un método de entender la direccionalidad de las actuaciones grupales, en una interrelación con la cultura (concebida como el proceso de significación), donde se trazan marcos de interpretación y estructuras de comprensión orientadas hacia la generación de sentido.
Actualmente, los elementos virtuales influyen en las culturas tradicionales y se configuran para crear símbolos, en donde las situaciones que se viven en la vida cotidiana viajan a través de canales de información digitales creados por los usuarios hasta convertirse en nuevas realidades; de esta manera aparecen nuevos actores y medios para transformarse en ambientes culturales. Con la aparición de tantos dispositivos y medios se originó una ruptura con el orden natural de convivencia con la naturaleza, lo que colocó al sujeto en condiciones que pretenden lineamientos y fronteras de actuación para regular el comportamiento, hay fragmentos de la vida cotidiana, hechos objetivos en el mundo, que se configuran solo por el acuerdo humano (Searle, 1997). Las invitaciones en la vida social persuaden a olvidarse del contenido real de los mensajes en un pensamiento unidireccional. Esta nueva comunicación representa una oportunidad para las empresas mediante factores que han contribuido a su transformación: clientes más inteligentes, saturación publicitaria, creación de comunidades y pérdida de credibilidad de los medios tradicionales.

En la comunicación existen procesos con elementos promotores de discursos, que incentivan experiencias culturales y finalmente desembocan en significaciones entre los miembros de una sociedad convirtiéndose en un mercado cada vez más poderoso, casi imperceptible para los que se quedan solamente con la interfaz que ofrecen los dispositivos. McLaren (1984), Giroux (1994) y Freire (1984) reconocen que existe comunicación manipulada, de una sola vía de aceptación en la realidad social, "la lógica de la necesidad y de la eficiencia [que han sido mediadas] a través del discurso político de la integración y el consenso" (Giroux, 1992, p. 102).

La estructura social tal y como se conoce actualmente promueve incapacidad para obrar y decidir los mejores intereses de los seres humanos al aceptar las proposiciones de los medios sin cuestionarlos. "Pensar y opinar con otros es rendirse inconscientemente a sus estándares. A eso le damos el nombre de actitud de conformidad social" (Allport en Blanco, Caballero y de la Corte, 2005, p. 259). Se vive inmerso en códigos opresores y modelos estándares que se contrarrestan con la noción de concientización, la que implica el pensamiento crítico y la acción para transformar y generar libertad mediante una lectura del mundo que significa tener una visión amplia de las formas de vida y la relación entre el lenguaje y los agentes transformadores como las facultades que todo humano posee para desarrollarse 
(Freire y Macedo, 1989). Estudiar la realidad social con base en los comportamientos culturales que tienen los seres humanos en las instituciones, requiere cuestionar teóricamente sus prácticas, representar la voz de aquellos que no lo pueden hacer como grupos marginados, entender y mencionar los lugares donde se llevan a cabo esos conflictos, para acercarse a formas distintas de aprender y adquirir conocimiento. No es solo cuestión de conocer las situaciones de poder y resistencia, es dar voz a los significados de los silenciados y oprimidos, los que son invisibilizados; sin embargo, están en riesgo latente de convertirse en una parte más del consumo comunicativo.

La realidad social, al ser un conjunto de actuaciones multiformes de muchos sujetos que se comunican y relacionan entre ellos, está basada en las acciones colectivas, en las prácticas de interrelación que es consensuada, reproducida e incorporada en el proceso de socialización dinámica. "Nuestros comportamientos, actitudes, valores y formas de ver el mundo guardan un estrecho paralelismo con los valores y normas propias de los grupos a los que pertenecemos" (Blanco et al., 2005, p. 38). La conducta de los individuos se encuentra compuesta por apreciaciones implícitas que la condicionan y hacen posible el proceso para significar y dar estructura a las cosas.

La sociedad moldea a los adolescentes por medio de códigos estandarizados como reglas de conducta, uniformidad en la ropa y en las aulas, procesos pedagógicos de enseñanza, estilos de aprendizaje, expectativas del docente y procesos de clasificación. Existen "fuerzas combinadas por las que los estudiantes son inducidos a cumplir con las ideologías dominantes y las prácticas sociales referidas a la autoridad, la conducta y la moralidad" (McLaren, 1984, p. 224). Generalmente los que ejercen el poder reprimen a los adolescentes cuando existen brotes de reflexividad para oponerse a los paradigmas establecidos y dejarse seducir por lo que en esta modernidad aparece como símbolos multimedia en la búsqueda de diversión y entretenimiento principalmente (Barinaga, 1994).

Los adolescentes que han sido incorporados a una institución, bajo marginación, pobreza, rechazo y maltrato, generalmente están relacionados con situaciones de analfabetismo y exclusión social, de modo que son vulnerables ante las envestidas del engaño discursivo en una comunicación unidireccional, en tanto que no exista un proceso de significación para trans- formar la manera de pensar a través de una reflexión sobre la situación socio-cultural, al interesarse por los problemas de su entorno y desear hacer un cambio en su comunidad (Reguillo, 2007). El desafío es que no hay preocupación por conocerlos como individuos en el entramado de lo que significan como agentes de cambio, quienes se vuelven críticos a medida que entienden su propia situación. En muchos casos estos actores son reprimidos cuando existen brotes de reflexividad (McLaren, 1984).

Al tener en cuenta esta postura que se ha planteado sobre la comunicación y la situación actual, las preguntas que surgieron fueron: ¿Qué sentido de la comunicación han construido los adolescentes de una institución encargada del cuidado de huérfanos, abandonados o con problemas intrafamiliares?, ¿cuál es el mejor enfoque y metodología apropiadas para investigar en este tipo de contextos?, ¿cuáles serían las categorías, subcategorías y dimensiones de estudio?, ¿es posible intervenir en estos grupos para motivar la concientización y la reflexión de los menores hacía una visión crítica?

La tesis de que la comunicación desempeña en México una función política-económica entre los individuos es la base principal de una investigación de corte social, que tiene el objetivo general de interpretar el sentido de la comunicación de catorce adolescentes de secundaria en una Casa Hogar en Tuxtla Gutiérrez, Chiapas, para conocer, identificar y analizar los procesos para comunicarse, a través de un enfoque crítico, mediante tres acciones específicas: 1) Conocer las bases bajo las que se establecen los procesos de comunicación, por medio de las historias, experiencias de vida, costumbres, tradiciones y trayectorias discursivas. 2) Identificar la relación que existe entre sujeto, cultura y poder en la producción social del sentido. 3) Analizar los datos, a través de la triangulación de las categorías, subcategorías y dimensiones para reconocer si existen códigos opresores y modelos estándares que se contrarresten con la noción de concientización.

La exploración se basó en un enfoque crítico, el cual incentivó el desarrollo de las narrativas e historias de vida, la construcción y organización del conocimiento, la cual se apoyó en la metodología cualitativa con la combinación de dos perspectivas: la de interpretación y la Investigación Acción Participativa (IAP). La primera se utilizó como una estrategia en la documentación de procesos sistematizados y en las dinámicas de trabajo en grupo (Elliott, 1997) y tuvo por objeto promover procesos participativos de 
intervención social. La segunda consistió en la redacción de los hallazgos obtenidos, pero enriquecidos con referentes previos, la indagación de sus actuaciones de acuerdo a la situación, para la elaboración de descripciones y abstracciones de los datos (Gimeno y Pérez, 1992).

\section{MARCO TEÓRICO. SENTIDO DE LA COMUNICACIÓN}

En este estudio se consideran las relaciones objeto-sujeto de los procesos comunicativos de aceptación, omisión y resistencia, lo que se hace en consenso al tomar en cuenta la percepción de la realidad social y como un terreno cultural de grados de acomodación. Existen dimensiones en la lucha por el control del sentido, mediante códigos y modelos impuestos, a través de los soportes y los procesos mediáticos involucrados que ejercen dominio en el campo de la negóciación. Un instrumento de análisis social son las historias de vida, las cuales permiten conocer la producción ordinaria de significados, donde las reglas, los roles y los valores son tres maneras de entender que ocurre cuando se pasa a formar parte de un sistema de autoridad y la influencia en la producción del sentido.

El sentido social es de lo que se percibe como realidad para un grupo o comunidad, el cual puede ser consciente o inconsciente en los procesos comunicativos. Se encuentran interrelacionados el objeto y el sujeto en la vida cotidiana "por sus múltiples y diversas formas de asociación y reciprocidad que tienen los seres humanos en el desarrollo de acciones tendientes a establecer intenciones y significados sociales" (Gimeno y Pérez, 1992, p. 353), que permiten incorporarlos a su conciencia y se construyen de manera condicionada porque está en conflicto constante debido a la red de relaciones y de historicidades determinadas; de este modo se resisten los modelos y se omiten otros, depende de posiciones y poder en una relación dialógica consensuada.

La percepción de la conciencia del sentido, empieza con la experiencia, "con el flujo de los signos de los que estamos rodeados, que van y vienen entre nosotros para dar sentido a la dinámica social, la vida cotidiana y el orden de cosas" (Toledo y Sequera, 2015, p. 3). Las instituciones adoptan, seleccionan y discriminan información de acuerdo a los intereses sobre las adolescencias resguardadas, en las cuales los menores crean un sentido de vida que objetivan en la realidad social en forma de prácticas cotidianas a través de procesos de comunicación. Goffman (2001) la define como un mecanismo en el cual se inflige poder, una herramienta de control social, las cuales pueden ser abiertas o cerradas y que adquieren forma material, absorben tiempo e interés de sus miembros.

La producción de sentido debe apreciarse como un terreno cultural que se caracteriza por grados de acomodación, impugnación y resistencia, donde los sujetos "aprenden a apropiarse críticamente del conocimiento existente fuera de su experiencia inmediata para ampliar su comprensión de sí mismos, del mundo y de las posibilidades para transformar el medio" (McLaren, 1984, p. 224; Giroux, 1992, 1993). Los sistemas simbólicos que sostienen la cultura y permiten la actividad social, la comunicación entre los seres humanos y la comprensión del mundo son los componentes de la actividad vital y primaria. Por ello se afirma que el símbolo instaura una realidad social (Amador, 2015).

En la producción del sentido hay dimensiones comunicacionales que se producen en el contexto de intereses militantes, matemáticos, cibernéticos, tecnológicos y económicos en una lucha por el control, cuyo análisis creativo les posibilita la comprensión de su situación. Giroux (1994) calcula su constitución sobre una vida direccionada y formas de resistencia a los códigos democráticos. Weber (1978) afirma que los sujetos también pueden ser manipulados por medio de símbolos procedentes de la subjetividad a través de la religión que aparece compitiendo por un lugar simbólico de las comunidades y gana credibilidad social por su crítica al modelo neoliberal que genera exclusión y pobreza, el cual es monopolizado por un cuerpo de especialistas.

El sentido que crean los seres humanos se constituye en muchos casos de las imposiciones de una vía direccionada de códigos impuestos "que favorecen la sumisión a normas que alientan el fanatismo, a teorías que culpan a la víctima del oprobio que sufren, a climas sociales que se cimientan en el valor de la obediencia a modelos de educación [para aceptar] el conformismo" (Blanco et al., 2005, p. 45); pero también, lo conforman las formas para resistir modelos al crear una falsa conciencia y un ocultamiento de los verdaderos intereses comunicativos, donde el capital trabaja y lo que vale es el dinero. En este punto, "el concepto de moda es asumido como categoría fundamental para la comprensión y asignación de los valores de la realidad" (Pasquali, 2007, p. 43). La vanguardia, 
lo exótico, lo inmediato, el aquí y el ahora son los elementos que constituyen la destrucción del sentido crítico, que propicia la modificación del entorno, que puede utilizarse políticamente para contrarrestar los efectos de la dominación dentro y fuera de los limites escolares y como parte de la vida cotidiana.

Los medios son manipulados política y económicamente. Se observa el control de gobiernos y empresas para generar una audiencia pasiva. Se confiere al sistema coherencia y unidad relativa, una propia explotación donde los individuos se insertan de manera natural en sus actividades prácticas para participar de la reproducción. La idea es silenciar las verdades por medio de la coerción social mediatizada que banaliza la información, por medio de "un sistema de representaciones, indiscernible de la experiencia vivida de los individuos [... que], penetra sus costumbres, sus gustos, sus reflejos" al percibir homogéneamente casos aislados, pero llamativos (Mattelart, 1978, p. 35; Blanco et al., 2005). De esta manera, se crean conflictos transculturales que fuerzan a todos a adaptarse y a responder, al ser más permeables, flexibles y consumidores (Lipovetsky, 1990).

Los procesos mediáticos del sentido que tienen los procesos comunicativos se pueden estudiar por medio de análisis lógicos al identificar los códigos que subyacen en los productos culturales, los que ejercen un control social postulado como un sistema de orden, que implica un repertorio de reglas para generar un conjunto de mensajes indefinidos que se hacen "en el interior de una narrativa que combina una política de desesperanza con una sofisticada descripción de las supuestas sensibilidades y humores de la juventud creciendo en las condiciones amenazantes de la cultura posmoderna" (Giroux, 1994, pp. 291-292; Innerarity, 1987). La idea es acuñar precisamente esta idea para identificar de forma crítica cómo se objetivan en la vida cotidiana, donde esta deja de ser una cuestión de técnica de medios como instrumentos a una dimensión constituida de las prácticas sociales y de micro luchas (Saintout, 2008).

Al investigar procesos comunicativos hay que considerar las historias de producción ordinaria de significados, los análisis de clase sobre el lugar en el contexto macro social y la "concentración de lo inmediato, de los textos culturales y mediáticos que dominan el modo de consumo doméstico" (Sierra, 2005, pp. 221-222). La experiencia adquirida durante la vida de una persona en unión con las condiciones históricas se ha perdido; se vive a la sombra de la cultura dominante y se ve reflejada en las interpretaciones realizadas. Además del conocimiento de las formas de control ideológico y el análisis de las estructuras, las formas de lo esencial, las cuestiones insignificantes y aquellas manifestaciones del hombre de someterse al orden establecido.

Las historias de vida como instrumento de análisis social y construcción teórica, plantean problemas metateóricos, teóricos y metodológicos a las creencias tradicionales existentes en las ciencias sociales en torno a la comparabilidad de las teorías generales y su utilización con propósitos de predicción y control. (Sarabia, 1985, p. 165)

Al considerar adolescencias que han sido insertadas en un ambiente social institucionalizado se tiene que hablar de la autoridad dentro del marco general de procesos de influencia, el analizar las historias de vida proporciona elementos valiosos para entender la producción del sentido comunicacional como propuso Herbert Kelman (en Blanco et al., 2005, pp. 403-404) a partir de tres procesos básicos, sumisión, identificación e internalización:

1. La sumisión tiene lugar cuando alguien acepta la influencia procedente de otra persona simplemente para provocar por parte de ella una reacción favorable o evitar una reacción hostil, para ganar una recompensa o para evitar un castigo. [...], refleja una orientación a leyes y normas. 2. La identificación ocurre cuando un individuo adopta una conducta asociada con la relación con otra persona o con un grupo que es satisfactoria para la propia autodefinición [...], el modelo del rol del agente de influencia. 3. La internalización [...] ocurre porque hay una coincidencia entre el agente de influencia y el sistema de valores del sujeto.

En esta postura las historias de vida proporcionan a los adolescentes una reclamación poderosa de singularidad dentro de la diáspora familiar que han sufrido. El resultado de una realidad social no se forma sin antecedentes que precedan de aquello que se ha visto, conocido o pensado en alguna etapa vivida. Estas experiencias se estudiaron con el propósito de extraer datos que mostraran el sentido construido por los adolescentes a través de tres categorías: un marco microsociológico, pautas psicosociológicas y las características individuales (Sarabia, 1985), las cuales permitieron reconocer el sentido que se percibe en consenso. Pensar la comunicación desde la cultura es enfocarse en la producción social del sentido, en el cual las reglas, los roles y los valores son las 
maneras que permiten entender que ocurre cuando se pasa a formar parte de un sistema de autoridad y se tienden a hacer cambios en la estructura interna del individuo, tales como: labrar una buena imagen de sí mismos y la sumisión ideológica al dejar de lado el propio sistema de creencias y valores (Blanco et al., 2005).

Los procesos de producción de sentido se dan en las prácticas de significación que conforman y reconfiguran el terreno cultural de la realidad social, creada y configurada bajo criterios de información selectiva. Derivado de lo anterior, se hace necesario reflexionar acerca del carácter de la verdad que estos establecen, para determinar qué tan verosímiles son sus contenidos; a fin de crear condiciones más equitativas entre las adolescencias institucionalizadas. Desde esta mirada, la teoría crítica permite rechazar el orden industrial capitalista cuyo fin es reproducir los valores de la sociedad existente y funcionar a favor de la cultura dominante, donde "la cultura incluye "mapas de significados' que, a través de una lectura semiótica, puede leerse el sentido que tienen los "rituales, lenguajes y sistemas de significado" (Borquez, 2006, p. 167), se habla de entender la realidad para sobreponerse a las estructuras sociales, políticas y culturales a través de la creatividad, derivados de la acción y reflexión (Freire, 1984).

En los procesos de comunicación el sujeto puede transformar el sentido de sus prácticas e interferir en la estructura establecida como la realidad social formada, "el que piensa sintetiza, historiciza y niega, puede ser considerado un infiltrado o enemigo del progreso" (Pasquali, 2007 , p. 43). Un recorrido crítico podría incluir la definición de objetos y estrategias de estudio, las investigaciones en el campo y la inclusión a la problemática de la cultura comunicativa a través de los medios y otros recursos multimedia. Esta visión crítica está basada en la generación de significados, articulación de la moral, un lenguaje ideológico, el poder de la voz y alfabetización y mediante la importancia del diálogo (Freire y Macedo, 1989). La liberación de estructuras y de modos prescritos e implícitos en el modo de vida permiten la construcción de un aprendizaje conjunto, con nuevas formas de hacer las cosas, distintos modos de interpretar la diversidad (Godenzzi y Pérez, 1997) y aceptar a los otros, entendiéndolos desde su propia forma de vida, no importando las diferencias existentes.

\section{METOdOLOGÍA. PROCESO EN LA INDAGACIÓN DEL SENTIDO COMUNICATIVO}

Las categorías de los instrumentos de análisis social y los aspectos considerados en cada una fueron: 1) Un marco microsociológico (MS), que se enfoca en la agencia social individual: la perspectiva temporal, ecología social y condiciones socioeconómicas de vida; 2) Pautas psicosociológicas (PS), que intervienen en los procesos de interacción y comunicación humana: la familia y los grupos, pautas culturales de valores, normas, expectativas y roles; y 3) Características individuales $(\mathrm{Cl})$ que definen la individualidad: auto descripciones e interpretaciones, intereses, actividades ocupacionales y de tiempo libre, fines, aspiraciones y conflictos, de sí mismo y de personalidad. En cuanto a las subcategorías obtenidas fueron: instrumental, valorativa, pertenencia, seguridad, disciplinar, religiosa y poder en sus formas de sentido: óptimo, real y figurativo.

Cuando se habla del sentido óptimo se refiere al ideario y las expectativas (PS), determinadas por sus deseos y anhelos de lo que debería ocurrir en su vida. El sentido real describe los roles, sentimientos y frustraciones, con base en la experiencia personal de cada adolescente (MS). Y la forma del sentido figurativo está representada por una figura representativa en la vida de los menores ( $\mathrm{Cl}$ ). En el caso de las dimensiones tratadas, Las de naturaleza objetiva se refieren a los hechos tangibles, observables, que parten de una perspectiva temporal (MS) o un producto humano; mientras las subjetivas no se pueden tocar, pretenden un significado de las cosas.

Las historias fueron útiles en los catorce adolescentes (cinco hombres y nueve mujeres), quienes tienen trayectorias de abandono, rechazo, violencia familiar y orfandad. Todos de nacionalidad mexicana, nacidos en Chiapas de los municipios de Tonalá, San Cristóbal, la Concordia, Villaflores y Tuxtla. En general, las narrativas de vida se vieron representadas en los sentidos: disciplinario y encuadre de normas. Éstas se manifiestan en los adolescentes por la sumisión al control, dependencia incorporada y conformación.

Los temas de análisis social que se establecieron en la obtención de datos para la interpretación del sentido que tiene la comunicación en los catorce adolescentes de la Casa Hogar; a través de las trayectorias discursivas, historias y experiencias de vida fueron: la organización estructural y el discurso, las prácticas comunica- 
tivas y las relaciones sociales, los elementos de carácter simbólico: el significado de la palabra mamá y la religión, los medios tecnológicos y el consumo.

En la organización estructural de la Casa hogar existe un esquema vertical que es representado primero, por los administradores, quienes aparecen como los responsables directos del discurso impuesto y del personal encargado del orden funcional. El siguiente nivel Io conforman los maestros en los que están incluidas las directivas de cada nivel educativo para dar continuidad a la reproducción del sistema, pero con ajustes en la enseñanza particular del Centro establecido, los encargados integrados por los responsables de las secciones de hombres, mujeres, cuneros, las enfermeras, cocineras y jóvenes asignados que se encuentran en calidad de asistentes personales, denominados directamente por directivos y quienes asumen un papel de obediencia a los estatutos determinados por la estructura. Los grupos externos en los que se encuentran escuelas, ONG's, fundaciones, establecimientos mercantiles, políticos y donadores particulares, quienes se ajustan a las condiciones predeterminadas antes del ingreso en estos espacios y los familiares, porque no todos los adolescentes son huérfanos; algunos han sido recogidos de casas disfuncionales o tienen parientes quienes los visitan, lo cual se hace bajo supervisión estricta y regulada por organismos e instituciones designadas. En el nivel inferior se encuentran los adolescentes, para quienes se configura toda la organización. Se constató el desprecio por la estructura para escapar de la opresión y buscar estabilidad en sus vidas. Hay antecedentes de casos de fuga de la institución, de traslado y expulsión.

En el ambiente discursivo, hay una separación entre ser alguien o no ser nada, bien definida en las relaciones comunicativas hacia y entre los adolescentes.

Se les inculca que, si desean tener éxito deben ser obedientes, aceptar la disciplina, portarse bien y estudiar. Se entiende en la frase: "si no te preparas no vas a ser nadie", lo que les sugiere la toma entre dos opciones. De los casi mil menores que han pasado por esta institución, solo dos han podido concretar sus estudios medio y superior y no se conoce que alguno tenga estudios universitarios.

De acuerdo con la opinión de los administrativos, a los menores se les ha orientado para cooperar en las labores propias de la casa, el lavado de la ropa, la elaboración de comidas en coordinación con los encargados. Lo que se observó es que son asignados a diversas tareas y sancionados por medio de castigos, regaños, maltrato físico y/o expulsión de la Casa si no lo hacen.

Los directivos dicen haber conseguido la reintegración de menores a sus familias, mismos, aunque, en muchos casos, es la gestión administrativa de los familiares cercanos lo que permite que salgan al haber sido sustraídos de hogares disfuncionales. Son excepcionales los casos de adopción porque los requisitos son muy complicados.

Las prácticas comunicativas que se establecen tienen que ver con las relaciones con otras personas tanto en las mujeres como en los hombres de la siguiente forma:

Las adolescentes de la institución socializan con mujeres de la iglesia cristiana que consideran sus hermanas, amigas, compañeras y con las enfermeras que laboran en las instalaciones; no les gusta platicar ni relacionarse con hombres porque sienten que no las escuchan o que se burlan; su percepción respecto a las más pequeñas es que no las comprenden o no entienden lo que dicen; con las jovencitas de su misma edad creen que es complicado por no ser confiables. Tienen la certidumbre que la participación es complicada cuando se forma un grupo.

En el caso de los hombres, a ellos, les gusta entablar conversaciones con el personal, los amigos y compañeros; se mantienen en una hermandad y guardan la distancia para no compartir las cosas importantes con otras personas. Otros prefieren hablar solos para poder expresar sus secretos en un lugar tranquilo. No les gusta platicar ni relacionarse con los niños más pequeños porque creen que no entienden sus asuntos. Perciben que socializar es complicado cuando no pueden entenderse debido a que tienen diferentes gustos, personalidad y costumbres. También cuando no han estado juntos nunca o cuando ya han formado círculos de amistad en donde los nuevos o ajenos son diferenciados. En ocasiones la burla de los demás los reprime.

Por otro lado, las relaciones sociales establecidas entre los adolescentes son significativas (PS) cuando se trata de pautas culturales de valores que cumplen sus expectativas relacionadas a la subjetividad. Estos menores están ansiosos por ser escuchados y amados, les gusta que les den la oportunidad de expresarse y recurren a Dios como el Ser disponible en todo 
momento. Los intercambios se hacen con las siguientes personas:

El personal lo conforman: directivos, docentes, encargados de sección, enfermeras, equipo de limpieza y vigilancia, quienes se encuentran en una posición accesible con la cual establecen una relación estable (MS), por medio del diálogo establecen el intercambio de información y algunos artículos del exterior.

Los compañeros son un apoyo para relacionarse y sentirse en un ambiente de confianza, en el que pueden expresarse libremente en momentos de esparcimiento, pueden ser en ciertos momentos agresivos y denigrar a los demás con sus comentarios.

La interrelación con personas externas es de carácter empresarial, social, político y gubernamental en situaciones específicas.

Las empresas realizan gestiones de ayuda formando grupos para visitar sus instalaciones en días claves como el Día del Niño o en la Navidad, tras haber concertado una cita con los administradores.

En el aspecto social, los menores se relacionan con grupos pertenecientes a ONG's de Estados Unidos, Canadá, Francia, Brasil y Japón, quienes los visitan con proyectos de mejora continua en áreas específicas de infraestructura de la institución.

En la política, intervienen equipos de campañas electorales, los candidatos se presentan para ofrecerles regalos, una cajita feliz de alguna empresa de comida rápida y a cambio les hacen promesas de donaciones, toman fotografías y videos. Esto les produce felicidad porque obtienen un producto que ven en televisión, pero comprenden que están siendo usados para promocionar campañas políticas.

Los elementos de carácter simbólico del significado de la palabra mamá fueron determinados desde la subcategoría instrumental en sus dimensiones objetiva y subjetiva como una necesidad elevada de una relación filial directa.

En la subcategoría instrumental objetiva de los tres sentidos analizados se obtuvo:

En el sentido óptimo, una madre es quien mantiene limpia y ordenada la casa, quien los vio por primera vez en el momento del nacimiento, fueron los primeros brazos que les extendieron y la primera sonrisa que tuvieron.

En el sentido real fue quien los tuvo en su vientre y luego los dio a luz, la que sintió el dolor físico al nacerlos y siguió teniendo más hijos después de ellos, la persona que los bañaba, pero también en un plano negativo es alguien que nunca más vuelven a ver, a quien no conocerán, una persona que no les daba de comer, la causante de la separación de sus hermanos y, en cuestión económica, un ser que pierde el tiempo en cosas que no les beneficia.

En cuanto al sentido figurativo, es quien se esfuerza para que estudien una carrera, se preocupa para tengan comida, ropa, calzado, cama y escuela. La encargada de criarlos. Es quien trabaja para ganar dinero, los atiende en las enfermedades, les administra sus medicamentos y los abraza.

En lo que se refiere a la categoría instrumental subjetiva, los resultados fueron:

En el sentido óptimo es quien les cuida los pasos para no caer, los felicita cuando algo le enorgullece, observa una buena circulación en todo, se esmera para que tengan lo mejor, les enseña cosas buenas; es con quien pueden platicar sus sentimientos y lo que piensan, sobre todo lo que sucede en la casa; los apoya, ve y está con ellos, aunque pasen cosas buenas y malas, les da consejos, los hace sentir felices, no los ignora y los entiende.

En cuanto al sentido real no es solo la que tiene hijos porque no todas las madres son iguales, hay unas que se preocupan y les indican a ellos el error que como mujeres cometieron por la decisión que las condujo por un camino que no los incluía y otras a las que no les preocupa ver por las necesidades de sus proles; no son apoyo, no les enseñan, ni les interesan.

Por lo que se refiere al sentido figurativo, su madre se esmera, se interesa para que salgan adelante y sean alguien en la vida porque desea ver bien a sus hijos en un futuro, es el ser que siempre está con ellos en lo bueno y en lo malo, les da consejos para salir adelante, les enseña cosas que no sabían, en una sola frase es la mejor.

Las subcategorías: valorativa, de pertenencia, seguridad, disciplinar, religiosa y uso del poder se han agrupado con la misma clasificación dentro de la tabla 1 . En la cual, se han incluido las palabras con las cuales los catorce adolescentes describen a sus madres. El sentido de tener un hogar, no es un hecho aislado, tiene que ver con circunstancias institucionales por parte de las personas al frente de ellos, pero también es un asunto macrosocial. 
Tabla 1. Descripciones sobre el sentido de tener una madre en las diversas subcategorías

\begin{tabular}{|c|c|c|c|}
\hline $\begin{array}{c}\text { Subcategoría/ } \\
\text { Sentido }\end{array}$ & Óptimo & Real & Figurativo \\
\hline Valorativa & $\begin{array}{l}\text { Cariño, } \\
\text { amor, } \\
\text { paciencia, } \\
\text { aprendizaj } \\
\text { e, } \\
\text { sacrificio. }\end{array}$ & $\begin{array}{l}\text { Infelicidad, } \\
\text { irresponsa } \\
\text { bilidad, } \\
\text { desamor, } \\
\text { abandono. }\end{array}$ & $\begin{array}{l}\text { Amor, cariño, } \\
\text { sacrificio, } \\
\text { desinterés, } \\
\text { alguien } \\
\text { grande en } \\
\text { sus vidas. }\end{array}$ \\
\hline Pertenencia & $\begin{array}{l}\text { No existe } \\
\text { la } \\
\text { posibilidad } \\
\text { de } \\
\text { pertenecer } \\
\text { a un hogar } \\
\text { funcional. }\end{array}$ & $\begin{array}{l}\text { Abandono, } \\
\text { un } \\
\text { miembro } \\
\text { más de la } \\
\text { familia, } \\
\text { recuerdo, } \\
\text { anhelo, } \\
\text { adopción, } \\
\text { negocio. }\end{array}$ & $\begin{array}{l}\text { Pertenecen a } \\
\text { la Casa } \\
\text { hogar, no } \\
\text { hay opciones } \\
\text { en su } \\
\text { condición y } \\
\text { satisfacción } \\
\text { por la } \\
\text { aceptación } \\
\text { brindada. }\end{array}$ \\
\hline Seguridad & $\begin{array}{l}\text { La } \\
\text { guardiana } \\
\text { de sus } \\
\text { hijos como } \\
\text { tesoro } \\
\text { (protección } \\
\text { y cuidado). }\end{array}$ & $\begin{array}{l}\text { Abandono, } \\
\text { no } \\
\text { deseado, } \\
\text { perdida } \\
\text { por } \\
\text { adicciones, } \\
\text { desamparo } \\
\text { soledad, } \\
\text { muerte, } \\
\text { olvido. }\end{array}$ & $\begin{array}{l}\text { Responsabili } \\
\text { dad, } \\
\text { protección, } \\
\text { interés en } \\
\text { tiempos de } \\
\text { soledad. }\end{array}$ \\
\hline Disciplinar & $\begin{array}{l}\text { Ausencia } \\
\text { de } \\
\text { maltrato }\end{array}$ & Corrección & $\begin{array}{l}\text { Amor y } \\
\text { cariño al } \\
\text { darles un } \\
\text { cinturonazo, } \\
\text { justificado } \\
\text { par que sean } \\
\text { buenas } \\
\text { personas, } \\
\text { corrección } \\
\text { para evitar } \\
\text { que sean } \\
\text { rateros y } \\
\text { escojan el } \\
\text { camino } \\
\text { malo. }\end{array}$ \\
\hline Religiosa & $\begin{array}{l}\text { Sin } \\
\text { comentario } \\
\mathrm{s}\end{array}$ & $\begin{array}{l}\text { Sin } \\
\text { comentario } \\
\mathrm{s}\end{array}$ & $\begin{array}{l}\text { Importancia } \\
\text { del } \\
\text { acercamient } \\
\text { o a Dios } \\
\text { como } \\
\text { prioridad en } \\
\text { la vida. }\end{array}$ \\
\hline Uso del poder & No existe & Imposición & $\begin{array}{l}\text { Matriarcado, } \\
\text { la cabeza del } \\
\text { hogar, figura } \\
\text { impuesta, la } \\
\text { única opción. }\end{array}$ \\
\hline
\end{tabular}

Fuente: Elaboración propia. Nota: En la primera columna se aprecian las subcategorías de estudio, en las columnas subsecuentes aparecen las palabras que describen e significado de tener una madre, en opinión de los adolescentes de la Casa hogar, en cada uno de los sentidos.
Lo que representa una madre a nivel simbólico tiene su inicio con la experiencia de los hechos vividos, la trayectoria y las experiencias actuales de prácticas cotidianas, con las cuales se aprecia el direccionamiento del sentido hacia una vida que funciona alrededor de herramientas para la vida: ser mejor, ser buenos ciudadanos, servir de algo, en el cual la realidad social prepara para el trabajo inmediato. Se percibieron valores negativos respecto al significado de su madre biológica en sus vidas. El tener una figura materna es importante materialmente; aunque es relevante la justificación que le dan al maltrato y a la disciplina excesiva que reciben actualmente, permea una mezcla entre lo religioso, los valores y lo instrumental, tanto objetivo como subjetivo.

La religión como tema de análisis constituye una base de creencias adoptadas en primer lugar por los administradores, quienes filtran la información en lo que consideran más conveniente para sus propósitos. Este grupo se encarga de establecer las reglas, normas y formas de ideología con bases supremas. En este sistema los directivos de la educación preescolar, primaria y secundaria; los maestros seculares de cada grupo y asignatura, los dirigentes en las asociaciones seculares, los grupos visitantes, los considerados hermanos de la iglesia, realizan actividades durante la semana y las llamadas clases sabáticas. Los líderes de forma directa ayudan en la reproducción mediante:

La Escuela Bíblica. Se efectúa antes de empezar con el currículum entre los docentes y el personal en el salón de clases.

Los alumnos llevan a cabo su estudio con la ayuda de la Bible Lime (libro de enseñanzas de las escrituras) durante las horas de clase incluidas en su horario curricular.

Los pastores hacen su labor en sus respectivas capillas con discursos que invitan a seguir a Dios y a hacer su obra al llevar a cabo la misma tarea con otros que también sufren y tienen necesidades, esto tiene lugar en el culto religioso los domingos, al cual asisten los alumnos que así lo desean.

Los grupos religiosos están integrados por aquellos que vienen de iglesias cristianas compatibles con la doctrina, ya sean locales o extranjeras como la iglesia pentecostal The Bridge Church, que arriban cada año para adoctrinar en cursos intensivos o seminarios tanto a los niños, niñas y adolescentes como a los docentes con escrituras, cantos, presentaciones gráficas y apets. Si los adolescentes obe- 
decen y siguen la línea correcta de ser buenos les va bien; de lo contrario están en oposición al proceso y van por el camino de la perdición: se les niegan las bendiciones y se encuentran con castigos, sanciones, regaños, abstención de bienes materiales y negación de actividades, incluso aquellas que se desarrollan dentro de la casa.

Se obtuvieron dos conceptos básicos en esta etapa de la investigación en la apreciación de los menores, los cuales han sido adoptados como realidad social a partir de sus prácticas: buen cristiano y buena persona.

Buen cristiano. Se refiere a una persona que aprende a hacer cosas buenas en la vida y ayuda a otros con necesidades, es alguien que no se va por otras doctrinas o es engañado para adorar ídolos y hacer que otros crean en Dios.

Buena persona. Es aquel que enseña a otros como lo hicieron con él, ayuda a los que no tienen familia, trabajo o casa; hace el bien y no el mal; además, significa salir adelante y terminar los estudios.

Los adolescentes en su mayoría se involucran en cuestiones eclesiásticas por la obligatoriedad de la institución; sin embargo, hay quienes manifiestan su inconformidad y no participan abiertamente, porque prefieren no hablar del tema para no expresar sus verdaderos sentimientos que los lleven a un desorden u alteración que les provoque un daño por parte de los que ejercen el control. Otros se moldean y condicionan en un proceso de identificación ante la autoridad de acuerdo con los parámetros esperados, de modo que creen, esperan, se alimentan de la fe y desarrollan una esperanza en las palabras prometidas, en palabras de algunos de ellos dicen: "me da esperanza, me gusta mucho, me dan amor, es verdad". Los demás disfrutan de los beneficios temporales, las ventajas y recompensas que les ofrecen: salir de la Casa Hogar y convivir con sus compañeros y otras personas, recibir dulces, regalos, contacto físico por medio de los abrazos, gente con quien platicar y socializar.

En los medios tecnológicos, una de las formas de consumo de los adolescentes es a través del medio masivo disponible en la Casa Hogar: la televisión, la cual tiene una posición trascendental de entretenimiento aparentemente inofensivo y que ayuda a los administrativos a estimular una conducta que enseña religión y valores. En palabras de los directivos a la gente que desea pasarles una cierta programación dicen: "Tienen autorizadas películas de Disney y de la iglesia". Los menores opinan que les gustan porque los distrae y también aprenden a guiar su vida y comentan: "los personajes me ayudan a saber cómo comportarme”. El sentido mediático aparece como una mezcla de entretenimiento y una estrategia de poder para mantenerlos dentro de ciertos parámetros conductuales que fortalecen el consumismo. Lo ideológico está constituido por representaciones que sirven para dar sentido a todas sus prácticas. Para ellos es una costumbre, una realidad, una apariencia de vida válida, de aceptación social.

La comprensión del consumo de programación específica en estos medios se percibe a través de discursos públicos con las rutinas de la vida cotidiana. Los adolescentes en este sentído negocian porque para acceder a la parte subjetiva se debe tener un continuo diálogo con la cultura y las tramas de la comunicación. Otra forma, está determinada por los artículos que les compran los grupos que vienen como representación de las ONG's o particulares extranjeros, quienes los llevan de compras a las tiendas departamentales y les regalan lo que quieran los adolescentes. Los agentes de gobierno también contribuyen en la reproducción de este hábito, al prometerles que los Ilevarán a comprarles una cajita feliz con lo cual se observó que los adolescentes quedan muy complacidos y agradecidos con los políticos, quienes a cambio les toman fotografías y videos para promocionar sus campañas, las cuales son transmitidas en los medios de difusión masiva. Los menores hablan de marcas como Wilson, Under Armond, Reebok y de lugares comerciales como Burger King, McDonald's y Suburbia. Se han condicionado a recibir y esperan que sea de fabricantes reconocidos, cuando les dan algo diferente no les gusta, lo desechan o simplemente pierden el interés y los obsequian a otros niños dentro y fuera de la institución.

\section{RESULTADOS. CONSTRUCCIÓN DEL SENTIDO EN COMUNICACIÓN}

La interpretación ofrecida es el resultado de la triangulación de técnicas, métodos, perspectivas, dimensiones y categorías a través de metodologías de participación conjunta.

En las historias de vida se percibieron sentídos de estructura en los niveles: político, económico e ideológico, en los cuales, contrario a lo que maneja Althusser (en Castro, 2000), tiene que ver la subjetividad de los adolescentes, la cual se ve afectada y manipulada desde su 
construcción histórica hasta la visión concreta de sus prácticas cotidianas (Bonilla y Rodríguez, 1997). Existe un adoctrinamiento para conservar los lazos de los roles sociales al sistema previamente definido y establecerse como mecanismos legitimadores alejados de la verdad, como hace constar Castro (2000) y los cuales se sostienen por intereses políticos y económicos de los administradores. Los menores son colocados en relaciones de producción en la cual se aprecia lo temporal, la competencia, el desarrollo y el progreso (Schoijet, 1991) de sociabilidad global y posicionamiento de marketing. En estas actividades se expresan valores y expresiones en un encuentro con la mediación, que implica un manejo ideológico que hace notar Sierra (2005), en lo que Giroux (1992) llama banalidad del consumo y la seducción de las marcas. Con base en los datos, se trabaja una domesticación de los sentimientos sobre los catorce adolescentes para escoger el camino del bien. En el aspecto religioso se interpreta una relación dicotómica entre el bien y el mal, lo positivo y lo negativo, referenciada por Marc y Picard (1992). Se organiza el proceder en dos vías y se simplifican las acciones para poner reglas y códigos que permitan recompensar o castigar. Hacen uso de elementos subjetivos relacionados con el alma humana, la comunicación con seres considerados en una realidad social como supremos, la cual atraviesa las diversas dimensiones y las representaciones, de las que habla Sierra (2005), como espacios en la producción de sentido.

En las dimensiones de la realidad social tanto la objetividad y la subjetividad tienen un impacto en el comportamiento social que lo condicionan y hacen posible. En los hechos objetivos, se puso de relieve la postura instrumental-material de prácticas adquiridas, en un plano estructural, no tienen oportunidad de libertad de expresión o actuación. En cuanto a una visión subjetiva se relaciona directamente con la cultura, de un poder político-económico hacia la parte simbólica entre las cuales se han situado las subcategorías de pertenencia y seguridad emocional que les permite desarrollar el sentido valorativo, lo que constituye un sentido de manipulación ideológica. La supremacía del objeto sobre el sujeto permea en la Casa Hogar.

\section{A MODO DE CONCLUSIÓN. EDUCACIÓN CRÍTICA EN COMUNICACIÓN}

El empleo de las historias de vida como técnica de investigación del sentido en las prácticas comunicativas de la realidad social fue una herramienta eficaz para comprender la vida de los adolescentes de la Casa Hogar. Estas sirvieron para indagar en todas sus vertientes la relación social y psicológica, una reclamación poderosa de singularidad dentro de la diáspora familiar que han sufrido, mediante las cuales se puede aportar, discutir, aprender y propiciar la modificación de su entorno y contrarrestar los efectos de la dominación ejercida por la autoridad.

Las apreciaciones finales se definen por la triangulación de las categorías:

En las pautas psicosociológicas existe una relación entre el poder y la subjetividad determinada por un orden económico-cultural en las prácticas derivadas de la inculcación de valores. Se disponen y asumen en una posición mediabaja que determina los roles y etiquetados.

En el marco microsociológico hay una relación directa entre el poder, la economía y lo cultural. Se observan actitudes y comportamientos donde calculan el beneficio-riesgo para sacar la máxima ventaja de las oportunidades en la Casa Hogar, ya sea, prestigio, reconocimiento, status social y responsabilidades de confianza. Hay una lucha con la mediación a través del consenso para adquirir herramientas que ayuden en el enfrentamiento social al salir de la institución, con lo cual construyen el sentido de la conveniencia intergrupal e individual.

Los adolescentes objetivan por medio de sus prácticas la subjetividad a través de las características individuales. Las descripciones reflejan un sentido de inferioridad y dependencia, en la estandarización de procesos conductuales, se omiten sus intereses reales por la posición adquirida y existen conflictos en la construcción legítima de sentidos en medio de una estela social regulada.

En las perspectivas política, económica y cultural, los catorce adolescentes de la Casa hogar que participaron en la investigación, han construido el sentido de la comunicación a través de historias, experiencias y una trayectoria discursiva, con lo que se concluye:

En la política las relaciones son de clase con base en la estructura vertical, a través de sus prácticas sociales cotidianas como religión, normas, reglas, costumbres y tradiciones. 
El uso del poder es de tipo jerárquico, se actúa en su dimensión subjetiva y se establece una vía para llegar a ser buenos.

Disciplinariamente son sometidos a rigidez y obediencia, esto trae como consecuencia el sentido de fastidio o el deseo de escapar de la institución.

La religión es usada como un instrumento modelo de adoctrinamiento para la modificación del comportamiento y la adquisición de valores en el camino de llegar a ser buenos cristianos, una forma de fortalecer la obediencia y una herramienta de escape a la rigidez y un recurso para adquirir posición y status (la sumisión crea confianza en ellos frente a los administradores).

El sentido económico se centra en: un condicionamiento hacia los bienes materiales, la visión hacia el progreso y desarrollo, la construcción de un sentido instrumental-material, la inducción a una programación visual alienante; así como un posicionamiento de marketing.

Los menores creen que hay una responsabilidad social hacia ellos por su condición social y el contexto en el que se encuentran.

Hay un sentido de aprendizaje bancario que los ha conducido en la mayoría de los casos al hastío escolar, aburrimiento y mal desempeño.

Existen formas de resistencia a los códigos establecidos, las cuales no son externadas por el temor al regaño, castigo o expulsión. Hay negociaciones sobre el buen comportamiento que es usado como una mercancía de poder.

En un panorama general sobre los hallazgos: la producción de los significados, incluyendo las prácticas con los medios y sus diversas representaciones: cultura de consumo, objetos de producción industrial, religión, la figura de madre y la violencia justificada son síntomas de la problemática latente de comunicación en una relación desequilibrada, en las cuales se resalta la importancia de los adolescentes como sujetos que actúan en un marco de poder ejercido por los administradores de la Casa hogar. Los cuales, han sido normalizados en sus trayectorias y se presentan como una realidad social ante la exclusión, marginación y dominación en relación directa con los productos cotidianos, en los cuales hay una estrecha relación entre el sujeto, la cultura y el poder. Por otra parte, la perspectiva de la cultura como proceso de significación es modificada a través de la disciplina y el fortalecimiento de la parte instrumentalista donde la meta es ser buenas personas para la vida, lo que implica estudiar para obtener un buen trabajo, seguir el modelo de reproducción al enseñar a otros en las mismas condiciones los modelos aplicados al sujeto mismo. Este sentido es reforzado no por voluntad propia, es impuesta y obligada donde la parte subjetiva creativa queda intrascendente. Finalmente se determina que, si existen códigos opresores y modelos estándares que se contrarresten con la noción de concientización, mismos que les impiden tener una visión amplia de las formas de vida.

De acuerdo con los hallazgos, existe una necesidad de postular el enfoque crítico en los procesos comunicativos a fin de incentivar la reflexión e imaginación a través del diálogo en los adolescentes de la Casa hogar. Se sugiere fomentar una educación consensual, bidireccional e interactiva en la generación de cono-cimiento que promueva nuevas maneras de aprender y decidir los mejores intereses, a través de procesos críticos, en los cuales los participantes: deliberan, significan, toman decisiones, gestionan, configuran valores, crean, aprenden, juegan, construyen, imaginan, seleccionan, piensan, opinan y objetivan sus subjetividades por medio de sus actuaciones desde su propia postura para cuestionar las estructuras opresivas tanto económicas, políticas y culturales en las que se encuentran inmersos.

Algunas sugerencias para propiciar el sentido crítico son: 1) Promover ejercicios reflexivos a los responsables en la atención pedagógica-educativa de los adolescentes, a fin de solucionar las carencias formativas que ponen de manifiesto una educación bancaria, de comunicación direccional vertical. 2) Proponer lecturas que estimulen una lectura de la realidad social y la imaginación de mundos posibles. 3) Fomentar el diálogo y la escritura por medio de dinámicas comunicacionales de expresión subjetiva. 4) Motivar la creación de sistemas autodidactas que desnormalicen la pantalla de la realidad social y les permita ser agentes y actores de su propio sentido.

\section{REFERENCIAS BIBLIOGRÁFICAS}

- Amador, J. (2015). Comunicación y cultura: conceptos básicos para una teoría antropológica de la comunicación. México: LIBRUNAM. Recuperado de: http://www.libros.unam.mx/digital/V8/2.pdf.

- Anolli, L. (2012). Iniciación a la psicología de la comunicación. Significación y función de los 
procesos comunicativos. Barcelona: Universitat Barcelona.

- Barinaga, R. (1994). Notas sobre la crítica a la modernidad, de Alan Touraine. Revista de servicios sociales Zervitzuan, 26, 4-7 Recuperado de: http://www.zerbitzuan.net/documentos/zerbitzua n/ZERBITZUAN\%2026.pdf.

- Blanco, A.; Caballero, A. y de la Corte, L. (2005). Psicología de los grupos. Madrid: Pearson. Recuperado de:

https://www.academia.edu/11981430/Psicolog\% C3\%ADa_de_los_grupos_-

_Amalio_Blanco_._Amparo_Caballero_._Luis_de_la_C orte.

- Bonilla, E. y Rodríguez, P. (1997). Más allá del dilema de los métodos. Bogotá: Uniandes.

- Borquez, R. (2006). Pedagogía crítica. México: Trillas.

- Castells, M. (1994). Flujos, redes e identidades: una teoría crítica de la sociedad informacional. En Nuevas perspectivas críticas en educación (pp. 1553). Barcelona: Paidós.

- Castro, S. (2000). Teoría tradicional y teoría crítica de la cultura. La reestructuración de las ciencias sociales en América Latina. Santiago Castro-Gómez. Bogotá: Santafé CEJA.

- Doelker, C. (1982). La verdad manipulada. Radio, televisión, cine, prensa. Barcelona: Gustavo Gili.

- Elliott, J. (1997). El cambio educativo desde la investigación acción. Madrid: Morata.

- Freire, P. (1984). La importancia de leer y el proceso de liberación. México: Siglo XXI.

- Freire, P. y Macedo, D. (1989). Alfabetización. Lectura de la palabra y lectura de realidad. Barcelona: Paidós.

- Gimeno, J. y Pérez, A. (1992). Comprender y transmitir la enseñanza. Madrid: Morata.

- Giroux, H. (1992). Teoría y resistencia en educación. México: Siglo XXI.

- Giroux, H. (1993). La escuela y la lucha por la ciudadanía. México: Siglo XXI.

- Giroux, H. (1994). Pedagogía y política de la esperanza. Teoría, cultura y enseñanza. Buenos Aires, Madrid: Amorrortu.

- Godenzzi, J. y Pérez, C. (1997). Equidad en la diversidad. Reflexiones sobre educación e interculturalidad en los Andes y la Amazonia. Multilingüismo y educación bilingüe en América y España, Curso, CBC, pp. 19-30.

- Goffman, I. (2001). Internados. Buenos Aires: Amorrortu.
- González, O. y Díaz, M. (2014). La nueva comunicación. Conceptos, tendencias y aplicaciones. Madrid: Pirámide.

- Innerarity, D. (1987). Modernidad y postmodernidad. Anuario filosófico, 20 (1), 105129.

- Lipovetsky, G. (1990). El imperio de lo efímero. La moda y su destino en las sociedades modernas (pp. 232-269). Barcelona: Anagrama.

- Marc, E. y Picard, D. (1992). La interacción Social. Cultura, instituciones y comunicación. Barcelona: Paidós.

- Mattelart, A. (1978). La comunicación masiva en el proceso de liberación. México: siglo XXI.

- McLaren, P. (1984). La vida en las escuelas. Una introducción a la pedagogía crítica en los fundamentos de la educación. México: Siglo XXI.

- Pasquali, A. (2007). Comprender la comunicación. Barcelona: ILCE-Gedisa.

- Reguillo, R. (2007). Emergencia de culturas juveniles. Estrategias del desencanto. Colombia: Norma.

- Richard, N. (2011). Globalización académica, estudios culturales y crítica latinoamericana. En Mato, D. (coord.). Cultura y transformaciones sociales en tiempos de globalización (pp. 185-199). Recuperado de: http://bibliotecavirtual.clacso.org.ar/ar/libros/ma to/richard.

- Saintout, F. (2008). Los estudios socioculturales y la comunicación: un mapa desplazado. Revista Latinoamericana de Ciencias de la Comunicación, 8-9. Recuperado de:

http://www.eca.usp.br/associa/alaic/revista/r89/art_07.pdf.

- Sarabia, B. (1985). Historias de vida, en Revista Española de Investigaciones Sociológicas, (29), 165-186.

- Searle, J. (1997). La construcción de la Realidad Social. Barcelona: Paidós Ibérica.

- Sierra, F. (2005). Crítica cultural y cultura de masas. Institucionalización de los Estudios Culturales ante el cambio social. Revista de Redes.com, (2), 213-230.

- Schoijet, M. (agosto-septiembre de 1991). La ideología de la aceleración del progreso científico y técnico, Economía Informa, 32-39.

- Toledo, A. y Sequera, J. (2015). La producción de sentido: Semiosis social. Razón y palabra, (88). Recuperado de: http://www.razonypalabra.org.mx/N/N88/Varia/ 40_ToledoSequera_V88.pdf.

- Weber, M. (1978). The Prospects for Liberal Democracy in Russia. En Runciman, W.G. 


\section{ARTÍ́CULOS}

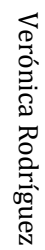

(ed.).Weber: Selections in Translation, (pp. 269-

286). Cambridge: Cambridge University Press. 